\title{
The Impact of New-Onset Atrial Fibrillation on Short- Term and Long-Term Mortality of Critically III Patients with Candidemia
}

\section{Zengli Xiao}

Peking University People's Hospital

Anqi Du

Peking University People's Hospital

Youzhong An ( $\sim$ bjicu@163.com )

Peking University People's Hospital

\section{Research Article}

Keywords: New-onset atrial fibrillation, critically ill, candidemia, mortality, risk factors

Posted Date: September 7th, 2021

DOI: https://doi.org/10.21203/rs.3.rs-415657/v2

License: (1) (i) This work is licensed under a Creative Commons Attribution 4.0 International License.

Read Full License 


\section{Abstract}

Background: Both new-onset atrial fibrillation (NOAF) and candidemia occurred frequently in critically ill patients, which are associated with poor outcomes. But, the association between NOAF and critically ill patients with candidemia is still uncertain. This study is try to identify the impact of NOAF on short-term and long-term mortality of critically ill patients with candidemia.

Methods: We retrospectively identified NOAF in all patients with candidemia admitted to a non-cardiac intensive care unit (ICU) from January 2011 to March 2018 in a teaching hospital. We categorized these patients into 3 groups (NOAF, Prior AF, No AF) and compared clinical information between groups. Risk factors for these patients' short-term and long-term mortality were also analyzed.

Results: Ninety-two patients with candidemia were identified from 2011 to 2018 . Among these patients, $26(28.3 \%)$ developed NOAF during their hospital stay. The multivariable logistic regression analysis indicated that stroke, anemia, Sequential Organ Failure Assessment (SOFA) score and NOAF were independent risk factors for in-hospital mortality and NOAF was also the independent risk factor for 1 year mortality.

Conclusions: There was a high incidence of NOAF in critically ill patients with candidemia, which was associated with in-hospital mortality and 1 year mortality after hospital discharge. Further multicenter studies should be conducted to help confirm this relationship and to find effective interventions that reduce short-term and long-term mortality.

\section{Introduction}

Atrial fibrillation (AF) is the most common arrhythmia found in postoperative and critically ill patients[14]. Several critical medical or surgical conditions have been proved to be associated with this cardiac arrhythmia. In intensive care unit, the development of atrial fibrillation can be triggered by fluid shift, neurohormonal disturbances, systemic inflammatory responses and sometimes be viewed as a response to physiological stress[5]. NOAF is both a marker of disease severity as well as a likely contributor to poor outcomes[6, 7].

Patients with fungal infections are a representative category of critically ill. Invasive fungal infection is a leading cause of ICU-associated infection and also a significantly predictor to mortality and morbidity in the critically ill[7-10]. Candida species has been reported as the most common cause of fungal disease, and the incidence rate of candidemia in ICU is nearly 10 to 20 times more than non-ICU patients[11, 12]. Patients with candidemia often have serious underlying diseases and the crude mortality is extremely high ranging from $36-63 \%[13-16]$. Moreover, among these patients with septic shock, candidemia is considered the clinical condition with the highest attributable mortality, ranging from 54\%-66\%[13-16].

Although available evidence provides enough information regarding a relationship between candidemia or NOAF and mortality, separately. But no previous study has determined the epidemiology and outcome 
of NOAF in candidemia patients. Therefore, the clinical importance of candidemia-associated NOAF is a matter of ongoing uncertainty. Therefore, we retrospectively identified NOAF in all patients admitted to our ICU with candidemia and analyzed its effect on patients' outcome.

\section{Materials And Methods}

\section{Study population}

We retrospectively identified and analyzed all patients admitted to a non-cardiac ICU with candidemia reported by the microbiological department of Peking University People's Hospital in China from January 2011 to March 2018. We investigated NOAF following candidemia hospitalization and categorized patients into 3 groups: 1) NOAF; 2) Prior AF; 3) No AF. The medical records of all patients were reviewed and the following information was collected: age, sex, height, weight, BMI, patient source (medical/surgical ward), underlying conditions (diabetes, hypertension, vascular disease, cerebral stroke, pneumonia, chronic renal dysfunction, solid tumor), the worst laboratory data within 3 days after admission to the ICU (hemoglobin level, temperature, serum total protein level, serum albumin level) and the worst SOFA score within 3 days after admission to the ICU and $\mathrm{CHA}_{2} \mathrm{DS}_{2}$-VASc score, complications including heart failure and stroke, short-term outcome data including death in hospital, length of ICU stay, length of hospital stay, and duration of mechanical ventilation, long-term outcome including death within 3 years after hospital discharge.

\section{Definitions}

We defined candidemia as the isolation of Candida species from at least one blood culture in patients with symptoms or signs of a systemic infection. NOAF was categorized if first detected by bedside telemetry and confirmed by 12-lead ECG during hospitalization or initiated pharmacologic therapy without previous AF. Anemia was defined as a hemoglobin level $<70 \mathrm{~g} / \mathrm{l}$. Hypoproteinemia was defined as a total protein level $<60 \mathrm{~g} / \mathrm{dl}$ or serum albumin level $<25 \mathrm{~g} / \mathrm{dl}$.

\section{Statistical analysis}

Data were analyzed with SPSS software version 21.0. For continuous variables, we used means with SDs. We compared independent groups using the $t$ test, and paired groups using paired sample $t$ test; One-way analysis of variance was used for comparison between multiple groups, and LSD method was used for post-hoc comparison. For categorical variables, we used percents and counts. The count data were described by case number ( $n$ ), and the difference between groups was tested by the Chi-square test. Factors with a $p<0.05$ in univariate tests were analyzed with a binary logistic regression model to identify the independent risk factors. The difference was statistically significant when $p<0.05$.

\section{Results}

Incidence of new-onset atrial fibrillation and baseline characteristics 
Ninety-two patients with candidemia were identified over a 7-year period from 2011 to 2018. Among these patients with candidemia, 26 (28.3\%) developed NOAF during their hospital stay and 7 (7.6\%) had AF history before hospital admission. Baseline characteristics of these patients are shown in table 1. Patients in NOAF and prior AF groups were older than no AF patients (mean age $74.04 \pm 11.41$ years and $81.29 \pm 5.94$ years vs. $67.12 \pm 16.24$ years), and more easier to complicate with heart failure $(38.5 \%$ and $42.9 \%$ vs. $10.2 \%)$, stroke ( $76.9 \%$ and $85.7 \%$ vs. $37.3 \%)$. Patients with prior AF and NOAF also had a higher $\mathrm{CHA}_{2} \mathrm{DS}_{2}$-VASc score $(5.14 \pm 2.12$ and $3.65 \pm 1.77$ vs. $2.83 \pm 1.81)$.

\section{Distribution of Candida species}

Distribution of Candida spp. of these patients was shown in Figure 1. Candida albicans was the most prevalent fungal species in patients with or without AF, followed by Candida parapsilosis, Candida glabrata and Candida tropicalis.

\section{Risk factors for short-term and long-term outcomes}

Compared with patients never developed AF, patients with NOAF or prior AF had a longer mechanical ventilation time ( $33.69 \pm 34.46$ days and $15.43 \pm 12.87$ days vs. $13.71 \pm 26.22$ days) and higher in-hospital death rate $(73.1 \%$ and $85.7 \%$ vs. $39 \%)$. And $85.7 \%$ of these patients with POAF and all patients with prior AF who survived when discharged from hospital died within 1 year, which is extremely higher than survivors with no AF.

In univariate analysis, in-hospital mortality was associated with cerebral stroke, heart failure, stroke, anemia, $\mathrm{CHA}_{2} \mathrm{DS}_{2}$-VASc score, SOFA Score, new-onset AF and total mechanical ventilation days as shown in Table 2. In logistic regression analysis, stroke, anemia, SOFA score and NOAF were independent risk factors for in-hospital mortality (Table 3 ).

For long-term outcome, the univariate analysis showed that NOAF, hypertension, solid tumor and stroke were associated with 1 year mortality after discharge (Table 4). And the logistic regression analysis indicated that NOAF was the independent risk factor for 1 year mortality (Table 5).

\section{Discussion}

Identification of prognostic factors associated with the outcomes of critically ill patients can be helpful to physicians in making treatment plan and discussing goals of care with patients and their relatives. Inhospital mortality is high in critically ill patients with candidemia, and its incidence rise when these patients complicated with NOAF. Although much remains to be understood, heightened awareness and early intervention may help reduce the burden among these patients.

The incidence of NOAF varies from 1 to $5 \%$ in regular inpatients[22, 23], $4.5 \%$ to $29.5 \%$ in mixed ICU[24], $8 \%$ to $10 \%$ inpatients with sepsis, $6 \%$ to $22 \%$ in patients with severe sepsis[25-27], $23 \%$ to $44 \%$ in patients with septic shock[28-30]. In our study, we demonstrated that $28.3 \%$ of all patients with candidemia 
developed NOAF which is much higher than previous study about NOAF in critical ill patients $(1.8 \%$ to 10\%) and similar with patients with septic shock[31-33]. This increasing incidence may support the hypothesis that a systemic inflammatory response, increased physiological stress and autonomic dysfunction are the major triggering factors for $\mathrm{AF}$ developing in these patients[34, 35].

Compared with patients who never developed $\mathrm{AF}$, the mechanical ventilation time in patients with POAF was significantly prolonged, which translated into more resource utilization and higher costs. Patients with NOAF also had an extremely high in-hospital mortality rate $(73.1 \%)$ and 1 year mortality rate after discharge from hospital (85.7\%). In multivatiable logistic regression analysis, NOAF was significantly associated with higher in-hospital mortality and 1 year mortality in patients with candidemia, which indicated that NOAF could be a predictor for poor outcomes of these patients.

According to previous study, Patients with NOAF had an increased risk of embolic stroke[36]. In our study, NOAF in patients with candidemia is associated with an increased risk of stroke compared with patients without AF. In multivariable analysis, stroke is also associated with in-hospital mortality. The possible explanations are that AF could cause embolic and ischaemic stroke which could be attributable to haemodynamic instability and biochemical disturbances and lead to clinical deterioration and death[3739].

The CHA2DS2-VASc score which include congestive heart failure; hypertension; age (65-74 years, $\geq 75$ years [doubled]); diabetes; previous stroke or TIA (doubled); vascular disease; and sex has been widely used for the assessment of thromboembolic risk and guiding antithrombotic therapy in patients with AF. Several studies have demonstrated that the higher $\mathrm{CHA}_{2} \mathrm{DS}_{2}$-VASc score is an independent predictor for mortality in patients with $\mathrm{AF}[40-44]$. In our study, $\mathrm{CHA}_{2} \mathrm{DS}_{2}$-VASc score was higher in patients with $\mathrm{AF}$ than those without $\mathrm{AF}$ and also a risk factor for in-hospital mortality even following a multivariate analysis, suggesting that $\mathrm{CHA}_{2} \mathrm{DS}_{2}$-VASc score may be a prognostic factor associated with the poor outcome in critically ill patients with candidemia.

Unsurprisingly, SOFA score as a organ dysfunction or failure evaluating system was closely related to inhospital mortality[40-44]. Anemia is a common clinical situation which could due to many factors including blood loss, nutritional deficiency, renal dysfunction, inflammation and so on. Same as previous studies, patients with anemia had an increased in-hospital mortality in our study. This result reminded us that we should correct anemia appropriately according to the cause.

\section{Strengths and limitations}

To our knowledge, this study is the first to demonstrate that NOAF was associated with in-hospital mortality and 1 year mortality in critically ill patients with candidemia, which suggested that NOAF maybe considered an important predictor of deterioration among these patients. There are several limitations in our study. Firstly, these data was retrospectively collected, and it is possible that the number of prior-AF cases may be inaccurate as many patients may have asymptomatic AF. Secondly, this is a single center study. The number of cases is relatively small making our conclusion not sufficient. Thirdly, majority of 
patients with NOAF died within 1 year after discharge from hospital, so there is insufficient data to assess long-term outcome. Therefore, the result of our study might not be fully generalizable, so a multicenter prospective, randomized controlled trial should be conducted to overcome these limitations.

\section{Conclusions}

Our study identified an important novel association between NOAF and poor outcomes including shortterm and long-term mortality in critically ill patients with candidemia. Further studies should involve larger, multicenter, prospective studies to get more accurate result and help the clinicians to adjust the treatment plan and communicate with patients and their relatives.

\section{Abbreviations}

NOAF: New-onset atrial fibrillation

AF: Atrial fibrillation

ICU: Intensive care unit

BMI: Body mass index

COPD: Chronic obstructive pulmonary disease

SOFA: Sequential Organ Failure Assessment score

\section{Declarations}

\section{Availability of data and materials}

The dataset used and analyzed in our study are available from the corresponding author on reasonable request.

\section{Acknowledgements}

None.

\section{Funding}

None.

\section{Author information}

Affiliations 
Zengli Xiao, Anqi Du, Youzhong An,

Contributions

YZA designed this study and revised the manuscript for important intellectual content; ZLX and AQD collected and analysed the data and ZLX drafted this manuscript. All authors read and approved the final manuscript.

Corresponding author

Correspondence to Youzhong An.

Ethics declarations

Ethics approval and consent to participate

This study was approved by the Medical Ethics Committee of Peking University People's Hospital.

Consent for publication

Not applicable.

Competing interests

The authors declare that there are no competing interests.

\section{References}

1. Kanji S, Williamson DR, Yaghchi BM, Albert M, McIntyre L. Epidemiology and management of atrial fibrillation in medical and noncardiac surgical adult intensive care unit patients. $J$ Crit Care 2012,27:321-326.

2. Guenancia $C$, Binquet $C$, Laurent G, Vinault $S$, Bruyere R, Prin S, et al.. Incidence and Predictors of New-Onset Atrial Fibrillation in Septic Shock Patients in a Medical ICU: Data from 7-Day Holter ECG Monitoring. Plos One 2015,10:e127168.

3. Arrigo M, Bettex D, Rudiger A. Management of atrial fibrillation in critically ill patients. Crit Care Res Pract 2014,2014:840615.

4. Labbe V, Bagate F, Cohen A, Voiriot G, Fartoukh M, Mekontso-Dessap A. A survey on the management of new onset atrial fibrillation in critically ill patients with septic shock. J Crit Care 2021,61:18-20.

5. Heinz G. Atrial fibrillation in the intensive care unit. Intensive Care Med 2006,32:345-348.

6. Bosch NA, Cimini J, Walkey AJ. Atrial Fibrillation in the ICU. Chest 2018,154:1424-1434.

7. Shoham S, Marwaha S. Invasive fungal infections in the ICU. J Intensive Care Med 2010,25:78-92.

8. Leroy $\mathrm{O}$, Gangneux JP, Montravers P, Mira JP, Gouin F, Sollet JP, et al.. Epidemiology, management, and risk factors for death of invasive Candida infections in critical care: a multicenter, prospective, 
observational study in France (2005-2006). Crit Care Med 2009,37:1612-1618.

9. Ostrosky-Zeichner L, Pappas PG. Invasive candidiasis in the intensive care unit. Crit Care Med 2006,34:857-863.

10. Meersseman W, Vandecasteele SJ, Wilmer A, Verbeken E, Peetermans WE, Van Wijngaerden E. Invasive aspergillosis in critically ill patients without malignancy. Am J Respir Crit Care Med 2004,170:621-625.

11. Epelbaum O, Chasan R. Candidemia in the Intensive Care Unit. Clin Chest Med 2017,38:493-509.

12. Playford EG, Nimmo GR, Tilse M, Sorrell TC. Increasing incidence of candidaemia: long-term epidemiological trends, Queensland, Australia, 1999-2008. J Hosp Infect 2010,76:46-51.

13. Barchiesi F, Orsetti E, Mazzanti S, Trave F, Salvi A, Nitti C, Manso E. Candidemia in the elderly: What does it change? Plos One 2017,12:e176576.

14. Pfaller MA, Diekema DJ. Epidemiology of invasive candidiasis: a persistent public health problem. Clin Microbiol Rev 2007,20:133-163.

15. Nucci M, Queiroz-Telles F, Tobon AM, Restrepo A, Colombo AL. Epidemiology of opportunistic fungal infections in Latin America. Clin Infect Dis 2010,51:561-570.

16. Bassetti M, Taramasso L, Nicco E, Molinari MP, Mussap M, Viscoli C. Epidemiology, species distribution, antifungal susceptibility and outcome of nosocomial candidemia in a tertiary care hospital in Italy. Plos One 2011,6:e24198.

17. Bassetti M, Righi E, Ansaldi F, Merelli M, Trucchi C, De Pascale G, et al.. A multicenter study of septic shock due to candidemia: outcomes and predictors of mortality. Intensive Care Med 2014,40:839845 .

18. Kollef M, Micek S, Hampton N, Doherty JA, Kumar A. Septic shock attributed to Candida infection: importance of empiric therapy and source control. Clin Infect Dis 2012,54:1739-1746.

19. Bassetti M, Giacobbe DR, Vena A, Trucchi C, Ansaldi F, Antonelli M, et al.. Incidence and outcome of invasive candidiasis in intensive care units (ICUs) in Europe: results of the EUCANDICU project. Crit Care 2019,23:219.

20. Guzman JA, Tchokonte R, Sobel JD. Septic shock due to candidemia: outcomes and predictors of shock development. J Clin Med Res 2011,3:65-71.

21. Bassetti M, Vena A, Meroi M, Cardozo C, Cuervo G, Giacobbe DR, et al.. Factors associated with the development of septic shock in patients with candidemia: a post hoc analysis from two prospective cohorts. Crit Care 2020,24:117.

22. Walkey AJ, Benjamin EJ, Lubitz SA. New-onset atrial fibrillation during hospitalization. J Am Coll Cardiol 2014,64:2432-2433.

23. Carrera P, Thongprayoon C, Cheungpasitporn W, lyer VN, Moua T. Epidemiology and outcome of newonset atrial fibrillation in the medical intensive care unit. J Crit Care 2016,36:102-106.

24. Yoshida T, Fujii T, Uchino S, Takinami M. Epidemiology, prevention, and treatment of new-onset atrial fibrillation in critically ill: a systematic review. J Intensive Care 2015,3:19. 
25. Annane D, Sebille V, Duboc D, Le Heuzey JY, Sadoul N, Bouvier E, Bellissant E. Incidence and prognosis of sustained arrhythmias in critically ill patients. Am J Respir Crit Care Med 2008,178:2025.

26. Goodman S, Shirov T, Weissman C. Supraventricular arrhythmias in intensive care unit patients: short and long-term consequences. Anesth Analg 2007,104:880-886.

27. Arora S, Lang I, Nayyar V, Stachowski E, Ross DL. Atrial fibrillation in a tertiary care multidisciplinary intensive care unit-incidence and risk factors. Anaesth Intensive Care 2007,35:707-713.

28. Kuipers S, Klein KP, Cremer OL. Incidence, risk factors and outcomes of new-onset atrial fibrillation in patients with sepsis: a systematic review. Crit Care 2014,18:688.

29. Guenancia C, Binquet C, Laurent G, Vinault S, Bruyere R, Prin S, et al.. Incidence and Predictors of New-Onset Atrial Fibrillation in Septic Shock Patients in a Medical ICU: Data from 7-Day Holter ECG Monitoring. Plos One 2015,10:e127168.

30. Klein KP, Frencken JF, Kuipers S, Ong DS, Peelen LM, van Vught LA, et al.. Incidence, Predictors, and Outcomes of New-Onset Atrial Fibrillation in Critically III Patients with Sepsis. A Cohort Study. Am J Respir Crit Care Med 2017,195:205-211.

31. Seguin P, Signouret T, Laviolle B, Branger B, Malledant Y. Incidence and risk factors of atrial fibrillation in a surgical intensive care unit. Crit Care Med 2004,32:722-726.

32. Meierhenrich R, Steinhilber E, Eggermann C, Weiss M, Voglic S, Bogelein D, et al.. Incidence and prognostic impact of new-onset atrial fibrillation in patients with septic shock: a prospective observational study. Crit Care 2010,14:R108.

33. Moss TJ, Calland JF, Enfield KB, Gomez-Manjarres DC, Ruminski C, DiMarco JP, et al.. New-Onset Atrial Fibrillation in the Critically III. Crit Care Med 2017,45:790-797.

34. Aviles RJ, Martin DO, Apperson-Hansen C, Houghtaling PL, Rautaharju P, Kronmal RA, et al.. Inflammation as a risk factor for atrial fibrillation. Circulation 2003,108:3006-3010.

35. Klein KP, Frencken JF, Kuipers S, Ong DS, Peelen LM, van Vught LA, et al.. Incidence, Predictors, and Outcomes of New-Onset Atrial Fibrillation in Critically III Patients with Sepsis. A Cohort Study. Am J Respir Crit Care Med 2017,195:205-211.

36. Walkey AJ, Wiener RS, Ghobrial JM, Curtis LH, Benjamin EJ. Incident stroke and mortality associated with new-onset atrial fibrillation in patients hospitalized with severe sepsis. JAMA 2011,306:22482254.

37. Massera D, Wang D, Vorchheimer DA, Negassa A, Garcia MJ. Increased risk of stroke and mortality following new-onset atrial fibrillation during hospitalization. Europace 2017,19:929-936.

38. Wolf PA, Abbott RD, Kannel WB. Atrial fibrillation as an independent risk factor for stroke: the Framingham Study. Stroke 1991,22:983-988.

39. Gialdini G, Nearing K, Bhave PD, Bonuccelli U, ladecola C, Healey JS, Kamel H. Perioperative atrial fibrillation and the long-term risk of ischemic stroke. JAMA 2014,312:616-622. 
40. Fuster V, Ryden LE, Cannom DS, Crijns HJ, Curtis AB, Ellenbogen KA, et al.. 2011 ACCF/AHA/HRS focused updates incorporated into the ACC/AHA/ESC 2006 guidelines for the management of patients with atrial fibrillation: a report of the American College of Cardiology Foundation/American Heart Association Task Force on practice guidelines. Circulation 2011,123:e269-e367.

41. Ntaios G, Lip GY, Makaritsis K, Papavasileiou V, Vemmou A, Koroboki E, et al.. CHADS(2), CHA(2)S(2)DS(2)-VASc, and long-term stroke outcome in patients without atrial fibrillation. Neurology 2013,80:1009-1017.

42. Cetin M, Cakici M, Zencir C, Tasolar H, Baysal E, Balli M, Akturk E. Prediction of coronary artery disease severity using CHADS2 and CHA2DS2-VASc scores and a newly defined CHA2DS2-VASc-HS score. Am J Cardio/ 2014,113:950-956.

43. Chua SK, Lo HM, Chiu CZ, Shyu KG. Use of CHADS(2) and CHA(2)DS(2)-VASc scores to predict subsequent myocardial infarction, stroke, and death in patients with acute coronary syndrome: data from Taiwan acute coronary syndrome full spectrum registry. Plos One 2014,9:e111167.

44. Rozenbaum Z, Elis A, Shuvy M, Vorobeichik D, Shlomo N, Shlezinger M, et al.. CHA2DS2-VASc score and clinical outcomes of patients with acute coronary syndrome. Eur J Intern Med 2016,36:57-61.

45. Vincent JL, Moreno R, Takala J, Willatts S, De Mendonca A, Bruining H, et al.. The SOFA (Sepsisrelated Organ Failure Assessment) score to describe organ dysfunction/failure. On behalf of the Working Group on Sepsis-Related Problems of the European Society of Intensive Care Medicine. Intensive Care Med 1996,22:707-710.

46. Ferreira FL, Bota DP, Bross A, Melot C, Vincent JL. Serial evaluation of the SOFA score to predict outcome in critically ill patients. JAMA 2001,286:1754-1758.

\section{Tables}

Table 1 : Baseline characteristics of patients with candedimia by AF status 


\begin{tabular}{|c|c|c|c|c|c|}
\hline \multirow[t]{2}{*}{ Variable } & \multicolumn{3}{|c|}{ Atrial Fibrillation } & \multirow[t]{2}{*}{$F / X^{2}$} & \multirow[t]{2}{*}{$P$} \\
\hline & No AF & New-onset AF & Prior AF & & \\
\hline Age & $67.12 \pm 16.24$ & $74.04 \pm 11.41$ & $81.29 \pm 5.94$ & 4.277 & 0.017 \\
\hline Gender & & & & 0.726 & 0.695 \\
\hline Male & $39(66.1)$ & 15(57.7) & $5(71.4)$ & & \\
\hline Female & 20(33.9) & $11(42.3)$ & 2(28.6) & & \\
\hline Height(cm) & $166.44 \pm 7.46$ & $164.35 \pm 8.42$ & $168.86 \pm 8.23$ & 1.149 & 0.322 \\
\hline Weight(kg) & $64.05 \pm 12.32$ & $59.88 \pm 9.44$ & $64.71 \pm 8.40$ & 1.312 & 0.274 \\
\hline BMI & $23.04 \pm 3.73$ & $22.27 \pm 3.94$ & $22.66 \pm 1.95$ & 0.390 & 0.679 \\
\hline Hospital adission & & & & 2.605 & 0.272 \\
\hline Medical ward & $16(27.1)$ & $9(34.6)$ & $4(57.1)$ & & \\
\hline Surgical ward & $43(72.9)$ & $17(65.4)$ & $3(42.9)$ & & \\
\hline \multicolumn{6}{|l|}{ Comorbid conditions } \\
\hline Hypertension & $27(45.8)$ & 12(46.2) & $5(71.4)$ & 1.733 & 0.421 \\
\hline Diabetes & 19(32.2) & $7(26.9)$ & $4(57.1)$ & 2.172 & 0.338 \\
\hline Vascular Disease & $15(25.4)$ & $6(23.1)$ & $3(42.9)$ & 1.059 & 0.589 \\
\hline Cerebral Stroke & $16(27.1)$ & $8(30.8)$ & $4(57.1)$ & 2.448 & 0.294 \\
\hline Pneumonia & 21(35.6) & 14(53.8) & $6(85.7)$ & 7.996 & 0.018 \\
\hline \multicolumn{6}{|l|}{ Hematological disease } \\
\hline Chronic renal dysfunction & $14(23.7)$ & $3(11.5)$ & $3(42.9)$ & 3.526 & 0.171 \\
\hline Solid tumor & $24(40.7)$ & $10(38.5)$ & $2(28.6)$ & 0.406 & 0.816 \\
\hline Heart Failure & $6(10.2)$ & $10(38.5)$ & $3(42.9)$ & 10.709 & 0.005 \\
\hline Stroke & $22(37.3)$ & $20(76.9)$ & $6(85.7)$ & 15.597 & 0.000 \\
\hline \multicolumn{6}{|l|}{ Laboratory data } \\
\hline Anemia & 21(35.6) & $11(42.3)$ & $3(42.9)$ & 0.417 & 0.812 \\
\hline Tempreture $₫ 38^{\circ} \mathrm{C}$ & 48(81.4) & 23(88.5) & $7(100.0)$ & 3.112 & 0.211 \\
\hline Hypoproteinemia & $53(89.8)$ & $26(100.0)$ & $7(100.0)$ & 2.683 & 0.272 \\
\hline $\mathrm{CHA}_{2} \mathrm{DS}_{2}$-VASc score & $2.83 \pm 1.81$ & $3.65 \pm 1.77$ & $5.14 \pm 2.12$ & 5.987 & 0.004 \\
\hline SOFA Score & $8.85 \pm 4.83$ & $9.31 \pm 4.21$ & $11.00 \pm 3.06$ & 0.720 & 0.489 \\
\hline
\end{tabular}




\begin{tabular}{|llllll|}
\hline Short-term Outcome(days) & & & & & \\
\hline Hospital length of stay & $50.73 \pm 40.93$ & $64.38 \pm 31.38$ & $55.00 \pm 35.49$ & 1.158 & 0.319 \\
\hline Total ICU length of stsy & $32.80 \pm 35.09$ & $52.65 \pm 37.25$ & $45.57 \pm 35.94$ & 2.895 & 0.061 \\
\hline Mechanical ventilation & $13.71 \pm 26.22$ & $33.69 \pm 34.46$ & $15.43 \pm 12.87$ & 4.623 & 0.012 \\
\hline Hospital Death & $23(39.0)$ & $19(73.1)$ & $6(85.7)$ & 12.431 & 0.002 \\
\hline Long-term Outcome & & & & & \\
\hline 1 year & $11(31.4)$ & $6(85.7)$ & $1(100.0)$ & 8.088 & 0.006 \\
\hline 2 year & $3(12.0)$ & $0(0.0)$ & 0 & 0.250 & 1.000 \\
\hline 3 year & $4(19.0)$ & $0(0.0)$ & 0 & 0.412 & 1.000 \\
\hline
\end{tabular}

Abbreviations: Cl: confidence interval; AF: Atrial fibrillation; SOFA score: Sequential Organ Failure Assessment score; ICU: Intensive care unit.

Table $2 \rrbracket$ Baseline characteristics for in-hospital mortality of patients with candedimia 


\begin{tabular}{|c|c|c|c|c|}
\hline \multirow[t]{2}{*}{ Variable } & \multicolumn{2}{|c|}{ Hospital Death } & \multirow[t]{2}{*}{$t / x^{2}$} & \multirow[t]{2}{*}{$\mathrm{P}$} \\
\hline & No & Yes & & \\
\hline Age & $68.18 \pm 16.08$ & $71.96 \pm 13.93$ & -1.207 & 0.231 \\
\hline Gender & & & 0.116 & 0.733 \\
\hline Male & $29(65.9)$ & $30(62.5)$ & & \\
\hline Female & 15(34.1) & 18(37.5) & & \\
\hline Height(cm) & $166.59 \pm 8.30$ & $165.52 \pm 7.38$ & 0.655 & 0.514 \\
\hline Weight(kg) & $64.66 \pm 13.23$ & $61.33 \pm 9.23$ & 1.386 & 0.170 \\
\hline BMI & $23.23 \pm 4.18$ & $22.39 \pm 3.13$ & 1.088 & 0.280 \\
\hline Hospital adission & & & 0.153 & 0.696 \\
\hline Medical ward & $13(29.5)$ & 16(33.3) & & \\
\hline Surgical ward & $31(70.5)$ & $32(66.7)$ & & \\
\hline \multicolumn{5}{|l|}{ Comorbid conditions } \\
\hline Hypertension & 17(38.6) & $27(56.3)$ & 2.854 & 0.091 \\
\hline Diabetes & 13(29.5) & 17(35.4) & 0.360 & 0.548 \\
\hline Vascular Disease & $8(18.2)$ & 16(33.3) & 2.733 & 0.098 \\
\hline Cerebral Stroke & $8(18.2)$ & $20(41.7)$ & 5.980 & 0.014 \\
\hline Pneumonia & $17(38.6)$ & $24(50.0)$ & 1.200 & 0.273 \\
\hline \multicolumn{5}{|l|}{ Hematological disease } \\
\hline Chronic renal dysfunction & $7(15.9)$ & $13(27.1)$ & 1.685 & 0.194 \\
\hline Solid tumor & 16(36.4) & $20(41.7)$ & 0.271 & 0.603 \\
\hline Heart Failure & $5(11.4)$ & $14(29.2)$ & 4.440 & 0.035 \\
\hline Stroke & 13(29.5) & $35(72.9)$ & 17.306 & 0.000 \\
\hline \multicolumn{5}{|l|}{ Laboratory data } \\
\hline Anemia & $12(27.3)$ & $23(47.9)$ & 4.151 & 0.042 \\
\hline Tempreture $₫ 38^{\circ} \mathrm{C}$ & $35(79.5)$ & $43(89.6)$ & 1.793 & 0.181 \\
\hline Hypoproteinemia & 41(93.2) & 45(93.8) & 0.012 & 0.912 \\
\hline $\mathrm{CHA}_{2} \mathrm{DS}_{2}$-VASc score & $2.68 \pm 1.79$ & $3.75 \pm 1.91$ & -2.764 & 0.007 \\
\hline SOFA Score & $6.59 \pm 3.76$ & $11.48 \pm 3.93$ & -6.082 & 0.000 \\
\hline
\end{tabular}




\begin{tabular}{|lllll|} 
New-onset AF & $7(15.9)$ & $19(39.6)$ & 6.346 & $\mathbf{0 . 0 1 2}$ \\
\hline Hospital length of stay & $50.52 \pm 38.73$ & $58.94 \pm 37.65$ & -1.056 & 0.294 \\
\hline Total ICU length of stay & $31.50 \pm 29.00$ & $46.60 \pm 41.22$ & -2.046 & $\mathbf{0 . 0 4 4}$ \\
\hline Total mechanical ventilation days & $11.70 \pm 21.87$ & $26.63 \pm 33.33$ & -2.558 & $\mathbf{0 . 0 1 2}$ \\
\hline
\end{tabular}

Abbreviations: Cl: confidence interval; AF: Atrial fibrillation; SOFA score: Sequential Organ Failure Assessment score; ICU: Intensive care unit.

Table 3囚Multivariable logistic regression model for in-hospital mortality

\begin{tabular}{llllllll} 
& B & S.E, & Wals & P & OR & \multicolumn{2}{c}{ OR95\% C.I. } \\
\cline { 7 - 9 } & & & & & & a & a \\
\hline Cerebral Stroke & 1.854 & 1.142 & 2.638 & 0.104 & 6.387 & 0.682 & 59.854 \\
\hline Heart Failure & -0.386 & 0.990 & 0.152 & 0.696 & 0.680 & 0.098 & 4.727 \\
\hline Stroke & 1.789 & 0.760 & 5.545 & 0.019 & 5.981 & 1.350 & 26.503 \\
\hline Anemia & 1.501 & 0.738 & 4.139 & 0.042 & 4.487 & 1.056 & 19.054 \\
\hline CHA $_{2}$ DS $_{2}$-VASc score & 0.111 & 0.261 & 0.183 & 0.669 & 1.118 & 0.671 & 1.864 \\
\hline SOFA score & 0.376 & 0.100 & 14.129 & 0.000 & 1.456 & 1.197 & 1.772 \\
\hline New-onset AF & 1.630 & 0.792 & 4.231 & 0.040 & 5.105 & 1.080 & 24.130 \\
\hline Total ICU length of stay & 0.020 & 0.012 & 2.848 & 0.091 & 1.021 & 0.997 & 1.045 \\
\hline Total mechanical ventilation days & -0.001 & 0.016 & 0.005 & 0.946 & 0.999 & 0.967 & 1.031
\end{tabular}

Abbreviations: Cl: confidence interval; AF: Atrial fibrillation; SOFA score: Sequential Organ Failure Assessment score; ICU: Intensive care unit.

Table $4 \rrbracket$ Baseline characteristics for 1 year mortality of patients with candedimia 


\begin{tabular}{|c|c|c|c|c|}
\hline \multirow[t]{2}{*}{ Variable } & \multicolumn{2}{|l|}{ 讴1峸 } & \multirow[t]{2}{*}{$t / X^{2}$} & \multirow[t]{2}{*}{ P } \\
\hline & No & Yes & & \\
\hline Age & $66.44 \pm 17.43$ & $71.28 \pm 14.22$ & -0.968 & 0.339 \\
\hline Gender & & & 2.185 & 0.139 \\
\hline Male & $14(56.0)$ & 14(77.8) & & \\
\hline Female & $11(44.0)$ & $4(22.2)$ & & \\
\hline Height(cm) & $165.48 \pm 8.91$ & $167.83 \pm 7.55$ & -0.909 & 0.369 \\
\hline Weight(kg) & $65.44 \pm 12.37$ & $62.83 \pm 14.56$ & 0.633 & 0.530 \\
\hline BMI & $23.82 \pm 3.95$ & $22.23 \pm 4.47$ & 1.229 & 0.226 \\
\hline Hospital adission & & & 0.497 & 0.481 \\
\hline Medical ward & $8(32.0)$ & $4(22.2)$ & & \\
\hline Surgical ward & $17(68.0)$ & 14(77.8) & & \\
\hline Hypertension & $13(52.0)$ & $4(22.2)$ & 3.882 & 0.049 \\
\hline Diabetes & $7(28.0)$ & $5(27.8)$ & 0.000 & 0.987 \\
\hline \multicolumn{5}{|l|}{ COPD } \\
\hline Vascular Disease & $3(12.0)$ & $5(27.8)$ & 0.836 & 0.360 \\
\hline Cerebral Stroke & $5(20.0)$ & $3(16.7)$ & 0.000 & 1.000 \\
\hline Pneumonia & $8(32.0)$ & $9(50.0)$ & 1.418 & 0.234 \\
\hline \multicolumn{5}{|l|}{ Hematological disease } \\
\hline Chronic renal dysfunction & $4(16.0)$ & $3(16.7)$ & 0.000 & 1.000 \\
\hline \multicolumn{5}{|l|}{$\mathrm{CVVH}$} \\
\hline Solid tumor & $7(28.0)$ & $12(66.7)$ & 6.344 & 0.012 \\
\hline Heart Failure & $1(4.0)$ & $4(22.2)$ & 1.841 & 0.175 \\
\hline Stroke & $4(16.0)$ & $9(50.0)$ & 5.736 & 0.017 \\
\hline \multicolumn{5}{|l|}{ Laboratory data } \\
\hline Anemia & $7(28.0)$ & $5(27.8)$ & 0.000 & 0.987 \\
\hline Tempreture $₫ 38^{\circ} \mathrm{C}$ & $20(80.0)$ & $14(77.8)$ & 0.000 & 1.000 \\
\hline Hypoproteinemia & $23(92.0)$ & $17(94.4)$ & 0.000 & 1.000 \\
\hline $\mathrm{CHA}_{2} \mathrm{DS}_{2}$-VASc score & $2.68 \pm 1.93$ & $2.78 \pm 1.63$ & -0.175 & 0.862 \\
\hline
\end{tabular}




\begin{tabular}{|lllll|}
\hline SOFA Score & $5.84 \pm 3.58$ & $7.72 \pm 3.92$ & -1.635 & 0.110 \\
\hline New-onset AF & $1(4.0)$ & $6(33.3)$ & 4.630 & $\mathbf{0 . 0 3 1}$ \\
\hline Hospital length of stay & $59.16 \pm 43.72$ & $40.78 \pm 28.08$ & 1.564 & 0.125 \\
\hline Total ICU length of stsy & $37.36 \pm 32.88$ & $24.56 \pm 21.73$ & 1.439 & 0.158 \\
\hline Total mechanical ventilation days & $13.08 \pm 25.28$ & $10.44 \pm 17.18$ & 0.383 & 0.704 \\
\hline
\end{tabular}

Abbreviations: Cl: confidence interval; AF: Atrial fibrillation; SOFA score: Sequential Organ Failure Assessment score; ICU: Intensive care unit.

Table 5囚Multivariable logistic regression model for 1 year mortality after discharge

\begin{tabular}{|llllllll|}
\hline & B & S.E, & Wals & P & OR & \multicolumn{2}{l|}{$95 \%$ C.I. } \\
\hline New-onset AF & 2.528 & 1.276 & 3.926 & $\mathbf{0 . 0 4 8}$ & 12.526 & 1.028 & 152.682 \\
\hline Hypertension & -0.944 & 0.820 & 1.326 & 0.249 & 0.389 & 0.078 & 1.940 \\
Solid tumor & 0.848 & 0.790 & 1.152 & 0.283 & 2.336 & 0.496 & 10.996 \\
Stroke & 0.769 & 0.856 & 0.807 & 0.369 & 2.157 & 0.403 & 11.542 \\
\hline
\end{tabular}

Abbreviations: Cl: confidence interval; AF: Atrial fibrillation.

\section{Figures}




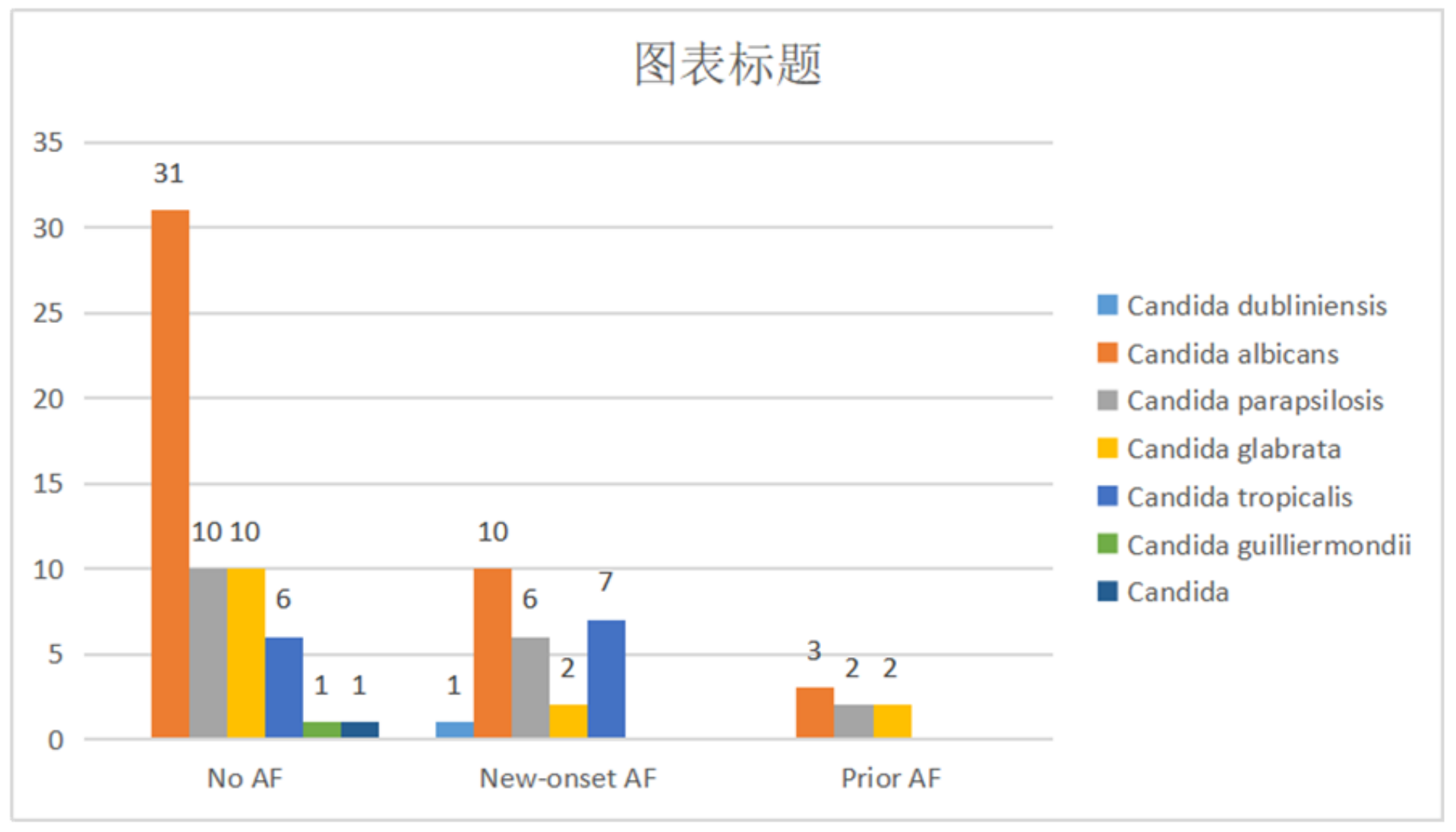

\section{Figure 1}

Distribution of candida spp. of these patients by AF status 